\section{Bush settles on technical innovator to head up NASA}

Tony Reichhardt

Michael Griffin, an engineer and physicist who builds planetary spacecraft, is the White House's popular selection for NASA's 11 th administrator.

If the appointment is confirmed by the Senate, it will be Griffin's second stint with the US space agency - he served as NASA's chief engineer and the head of its exploration office in the early 1990s. After that he worked for aerospace companies and for In-Q-Tel, a Virginia-based company that develops technology for the US Central Intelligence Agency. Since last April Griffin has headed the space department at the Johns Hopkins University Applied Physics Laboratory in Laurel, Maryland. The lab has become a main supplier of spacecraft for NASA planetary missions, such as the MESSENGER mission to Mercury and the New Horizons project to visit Pluto.

In the 1980s, as deputy for technology for the Strategic Defense Initiative, Griffin pioneered the concept of using small, smart spacecraft instead of big, expensive ones. This culminated in 1994's Pentagon-led lunar orbiter, Clementine, and influenced NASA's switch to 'better, cheaper, faster' missions. As the agency's associate administrator for exploration, he brought the same philosophy to the short-lived Space Exploration Initiative, a proposal by the first President George Bush to send astronauts to the Moon and Mars. Griffin turned to centres outside NASA for lunar exploration proposals in the hope of lowering mission costs.

Unlike his predecessor Sean O'Keefe, whose background is in accounting and government, Griffin is a space technologist. His roots lie in Maryland, the home state of Senator Barbara Mikulski, a Democrat and strong advocate of space science. Mikulski battled with O'Keefe over his decision to cancel servicing of the Hubble Space Telescope, and the question of whether to reverse that decision is one of many facing Griffin.

He inherits an agency that many critics say is too stodgy, and is not configured to carry out the current president's MoonMars initiative - just last week NASA announced plans to retire up to $15 \%$ of its workforce. Among the dilemmas facing the agency are how and when to retire the space shuttle, and what to do about the still uncompleted International Space Station.

Last year, Griffin co-chaired a study on human space exploration for the Planetary

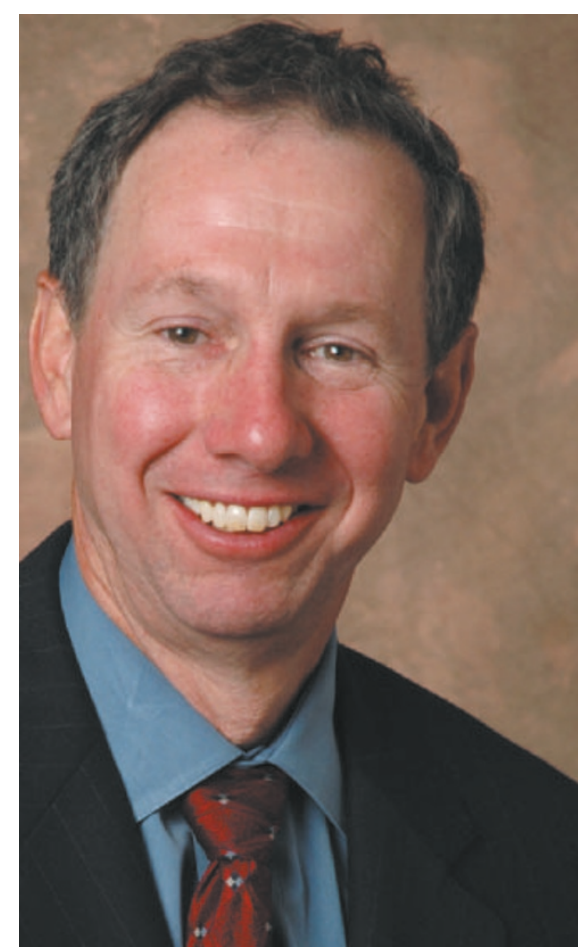

Michael Griffin: scientists praise the decision to appoint this pioneer of small, smart missions.

Society, which is based in Pasadena, California. The study recommended that NASA consider ending shuttle flights before the full station is built to save money for the exploration programme. In congressional testimony, Griffin said: "It is beyond reason to believe that [the space station] can help to fulfill any objective, or set of objectives, for space exploration that would be worth the $\$ 60$ billion remaining to be invested in the program."

Many in the field of space exploration welcome Griffin's technical know-how and his willingness to question old ways of doing business. Wesley Huntress, a former NASA head of space science who directs the Geophysical Laboratory at the Carnegie Institution of Washington, calls him "an honest person who says what he thinks".

News of Griffin's nomination won immediate praise from scientists and politicians, Democrats and Republicans alike. Alan Stern is a planetary scientist with the Southwest Research Institute in Boulder, Colorado, whose New Horizons mission is being built by Griffin's Applied Physics Laboratory. He says, "I really think he will be the best administrator that NASA has had in decades. I expect he will make NASA shine."
Global bomb-test monitor could give tsunami warnings

Declan Butler, Paris

Real-time data from seismic stations being built to detect nuclear tests may be made available to a proposed tsunami warning system.

The International Monitoring System (IMS) is currently used by a Viennabased section of the Comprehensive Nuclear Test Ban Treaty Organization (CTBTO) to check for unauthorized nuclear-weapons tests.

Lassina Zerbo, director of the organization's International Data Centre, announced the possible new use of its data at an international meeting at UNESCO in Paris from 3 to $8 \mathrm{March}$. The gathering was held to discuss technical aspects of the creation of a tsunami warning system for the Indian Ocean.

The IMS is potentially extremely useful. Its planned global network of 321 monitoring stations - of which some 130 are already in operation - will use seismic, hydroacoustic (underwater sound) and infrasound (sound frequency below that detectable by the ear) data to measure tremors. Data can also be relayed in real time around the globe by the CTBTO's satellite infrastructure.

But the move is highly sensitive politically. The CTBTO will make data available to UNESCO's Intergovernmental Oceanographic Commission (IOC), which will not pass the information to any other body or individual.

Initially the IOC will test the types of data that could be useful, and look at how these could be integrated into a warning system.

"We'll see in the next three months whether the data can be used for disaster warning systems," says the IOC's executive secretary, Patricio Bernal.

The Paris meeting also saw the agreement of a timetable for creating a system of tide gauges and seafloor pressure monitors for the Indian Ocean. By the end of this year, six new monitoring stations will be installed off the coasts of Malaysia, Thailand and Indonesia, and 15 others in the region will be upgraded to monitor sea levels.

By the end of this month, the United States and Japan will provide alerts on all seismic activity in the Indian Ocean region to round-the-clock contact points in the surrounding countries. But discussions on the final form and cost of the Indian Ocean system could take until the end of 2006, says Bernal. 